\title{
Tourism Distribution Channels
}

\section{By Mark Anthony Camilleri ${ }^{1}$, PhD (Edinburgh)}

How to Cite: Camilleri, M. A. (2018). Tourism Distribution Channels. In Travel Marketing, Tourism Economics and the Airline Product (Chapter 6, pp. 105-115). Cham, Switzerland: Springer Nature.

\begin{abstract}
The distribution channels link the customers with the businesses. For many years, the tourism businesses may have distributed their products and services through intermediaries. However, the latest advances in technology have brought significant changes in this regard. More individuals and corporate customers are increasingly benefiting of ubiquitous technologies, including digital media. The development of mobile devices and their applications, are offering a wide range of possibilities to the travel industry. Consumers are using smart phones and tablets to purchase tourism products. These issues have inevitably changed the structure of the tourism industry; in terms of control and value for money to consumers. In this light, this chapter describes the traditional and contemporary travel distribution channels as it raises awareness of the potential of new distribution technologies. Afterwards, there is a discussion on the role of digital media in the distribution chain as tourism businesses are increasingly selling directly to customers through the internet via websites and travel search engines. In conclusion, this chapter anticipates what the future holds for the distribution of travel and tourism products.
\end{abstract}

\footnotetext{
${ }^{1}$ Department of Corporate Communication, Faculty of Media and Knowledge Sciences, University of Malta, Malta. Email: mark.a.camilleri@um.edu.mt
} 


\subsection{Introduction}

Distribution channels enable customers to buy or gain access to travel products. Therefore, they may refer to all aspects of the link between the businesses and their customers (whether individual consumers, groups or corporate customers). In the last fifty years, the tourism service providers and their intermediaries have used technology to distribute their products and services. Many hotels and car rental companies are still utilising global distribution systems to sell their products to customers. This chapter suggests that tomorrow's business must continue to embrace innovative distribution technologies to improve their customer experience.

\subsection{The Distributive Chain}

Many businesses have often relied on intermediaries to deal with the passenger side of their business. The travel intermediaries are either travel agents or tour operators. The retail travel agents sell directly to the travelling public, whereas the tour operators (or travel organisers) are the wholesalers of the tourism industry. The latter intermediaries may usually purchase large blocks of airline seats, hotel rooms or tours, in advance, and then sell them as packages to other travel agents.

Thirty years ago, the use of intermediaries was quite advantageous to the tourism service providers; as they often facilitated the exchange process between the business and the consumer. They reduced the total cost of marketing, as they combined their sales efforts with the travel service providers. The intermediaries also helped to avoid heavy expenditures in retail marketing, as they provided brick-and-mortar (in terms of offline sales) opportunities in relatively small markets. Moreover, the travel agents provide additional services to customers (for example, they could support customers in their travel formalities, including visas and foreign currency).

\subsection{Air Travel Distribution}

Prior to the emergence of digital media, the leisure and business travellers did not have any other options, other than to make their reservations and ticketing through travel agents and / or sales offices. At the time, many airlines have opened their own sales offices, or have appointed 
general sales agents (GSAs) to represent them in different markets. GSAs were appointed to markets that were not served directly by an airline, or where the volume of passengers was insufficient to open ticket reservations offices. These GSAs were also paid a commission on the tickets they issued in their respective markets.

In the past, the travel trade claimed that many airlines were taking businesses from them, as the airlines wanted to exert control over their distributive chain. At the time, many travel agents used to sell airline tickets, package tours or even supplementary travel items. They also claimed commissions from different tourism service providers, including airlines. However, in the past decades, many international airlines have cut these commissions. As a result, the traditional brick and mortar intermediaries had to focus on improving their services and value proposition to survive in a tough competitive environment.

The new, no-commission world has been on its way since 1995, when airlines first started cutting down on the fees they paid travel agents to distribute their tickets. Small storefront travel agents were the most affected; as the larger agencies were capable of rebating commissions from corporate customers. Prior to the removal of the airline commissions, the travel agents generated their revenues through global distribution systems. They had access to information networks that allowed them to easily track the records of customers, from different airlines. However, the arrival of the internet has changed all that. Today, online travel agents as well as independent travellers could compare the airlines' fares, in a few clicks.

\subsection{Computer Reservation Systems}

In the 1950s, a few airlines and hospitality businesses started using computer reservations systems (CRSs) to automate their booking systems, or for inventory purposes. Eventually, these CRSs were improved to offer not only airline facilities, such as information concerning availability, but also provided booking services on a whole range of travel products, including; hotels, car hire et cetera.

Airlines started automating their distribution systems by installing software in their intermediaries' computer terminals. The main U.S. airlines behind this development were American Airline's Sabre and United Airline's Apollo. In 1976, United began offering its 
Apollo system to travel agents. Initially, these CRSs were single access, as the travel agents could only access single airlines. However, the marketing value of these convenient CRSs was indispensable and their development spread quickly to other parts of the world. The single access approach was soon replaced outside the United State with multi-access systems. European airlines also began to invest in CRSs in the 1980s. Many of them deployed their own reservations systems in their homeland, as there was a surge in demand for air travel. Videcom international handled about $97 \%$ of UK airline business trade bookings by 1987 . This system was replicated in other areas of the world, including the Middle East (DMARS), New Zealand, Kuwait (KMARS), Ireland, Caribbean, United States and Hong Kong, among others. Travicom was a trading name for Travel Automation Services Ltd. When British Airways (who by then owned $100 \%$ of Travel Automation Services Ltd) chose to participate in the development of the Galileo systems, Travicom changed its trading name to Galileo UK. In 1987, a consortium that was led by Air France and West Germany's Lufthansa has developed Amadeus, which was modelled on SystemOne. Amadeus Global Travel Distribution was launched in 1992. In 1990, Delta, Northwest Airlines, and Trans World Airlines formed Worldspan, and in 1993, another consortium (including British Airways, KLM, and United Airlines, among others) formed the competing company, Galileo International, that was based on Apollo.

CRS development took place rapidly as improved technology has changed the whole approach to reservations. Some initial problems were encountered with some CRSs, as they had built-in biases to give the operating airline a marketing advantage. However, measures were taken to force the elimination of these biases. Evidently, these CRSs were effective distributive forces for the travel and tourism industries. These CSRs allowed immediate direct bookings to be made and they provided supplementary services to customers. They enabled travel agents and airlines across the world to book instantaneously through the airlines' CRSs. The airline products were distributed across the world. Various consortia of airlines came together to develop their own CRS systems. At the time, the development costs of these CRSs were huge. It was also clear that the American (U.S.) systems were already well ahead in this field. As a result, various alliances formed between existing and developing CRSs which have made rapid progress with regard to their system development and the installation of work stations among travel agencies. With regard to the European CRS industry, just like their U.S. counterparts, have come under the scrutiny of regulatory authorities. Both the European Civil Aviation Councils and the European Community (i.e. the European Union) have developed codes of conduct for the operation of CRSs. Eventually; most airlines have outsourced their CRSs to 
Global Distribution Systems (GDSs) companies, which have enabled consumer access through Internet gateways.

\subsubsection{Global Distribution Systems}

The development of the GDSs offered ever-increasing services and searching power to tourism businesses. A GDS is a network that is operated by a company, which enables automated transactions between travel service providers (mainly airlines, hotels and car rental companies) as well as travel agencies. Travel agencies have traditionally relied on GDSs for services, products and rates, to provide travel-related services to end consumers. GDSs offered useful links to travel services, rates and bookings, thereby consolidating tourism products and services across all sectors. Modern GDSs typically allow users to book hotel rooms, rental cars, airline tickets, as well as other activities and tours. They also provide access to railway reservations and bus reservations in some markets, although these are not always integrated within the main system. Smaller companies such as KIU have developed customised GDS products that are aimed at niche markets including; the low-cost carrier segment, and small and medium-sized domestic and regional airlines.

GDSs differ from CRSs, as their reservation systems are used by service providers themselves (also known as vendors). Primary customers of GDSs are travel agents (both online and officebased). These intermediaries make reservations on the GDSs in real time. For instance, when airlines and travel agencies request a reservation from a service provider, the GDSs route their request to individual CRSs. This enables them to book flights, hotels, activities and associated services directly with the vendors who are part of GDS networks. The airlines who are members of the International Air Transport Association (IATA) could make bookings on other airline sectors. Their reservation systems have facilitated inter-airline bookings. Therefore, air travellers could book their entire itinerary, involving different flights on IATA carriers. The airlines' distribution and payment facility is led by IATA's settlement systems (ISS). Similarly, IATA's Billing and Settlement Plan (BSP) BSP is a system that is designed to facilitate and simplify the selling, reporting and remitting procedures of IATA's Accredited Passenger Sales Agents, as well as to improve financial control and cash flow for BSP Airlines. This is a worldwide system as BSP operates in 181 countries and territories. The system currently 
serves approximately 400 participating airlines with an on-time settlement rate of $99.99 \%$. In 2015, IATA's BSP processed \$230.3 billion (IATA, 2017).

The tourism industry's GDSs originated from traditional legacy models that were operated by airline vendors and travel agents. During the early days of CRSs, flight ticket reservations were not possible without a GDS. As time progressed, many airline vendors (including budget and mainstream operators) started adopting 'direct selling' strategies to their wholesale and retail customers (passengers). They have invested heavily in their own reservations' directdistribution channels and partner systems. These developments have led to a lower dependency on GDS systems. Recently, IATA announced its 'New Distribution Capability' (NDC), which is essentially an XML-based data transmission standard which provides a set of guidelines for communications between airlines and $3^{\text {rd }}$ party distributors. Specifically, NDC allows the sale of ancillary products (for example, baggage, meals, special seating, et cetera). Therefore, IATA's NDC holds the potential to help airlines boost revenue. Yet, there are still questions as to whether there will be any benefits stemming from reduced distribution costs. On average, the costs on the tickets sold through GDSs hovers around US\$12 per return ticket, which is 20times more when compared to selling tickets through direct channels for some airlines (Atmosphere Research Group, 2012). With airline profit margins under constant pressure, airlines are finding innovative ways to reduce their distribution costs by selling tickets to customers directly, rather than through $3^{\text {rd }}$ parties. Hence some experts are predicting that the GDSs may be phased out by 2020. For example, in 2015, Lufthansa Group announced that it was imposing an additional $€ 16$ charge when bookings are made through an external GDS, rather than from its own system. The German airline suggested that the costs of using external systems were much higher than their own. Several other airlines, including Air France-KLM and Emirates also stated that they were going to follow these developments. These issues suggest that airlines are reducing their reliance on dedicated GDSs.

On the other hand, many hotels and car rentals firms continue to take advantage from GDSs, particularly from the GDSs' last-minute inventory disposal which has provided them with additional operational revenue. In this case, the GDSs turned out to be a useful tool for them, as it facilitated their global outreach. These tourism businesses benefited from the GDS networks as they had lower marginal costs when compared to the airlines' distribution costs. 


\subsection{Online Sales via Websites}

The tourism industry has seen a number of interesting trends and developments for many airlines and their intermediaries. It may appear that the travel "distribution" is becoming like "e-commerce," with campaigns, offers, and channel marketing. For many years, the GDSs had a dominant position in the travel industry. Yet, new technologies are making fundamental changes in the structure of the travel industry, vis-à-vis, its distribution of products and services. To bypass the GDS and avoid their high fees, many airlines are distributing flights directly via their websites. Today, several airlines have closed their own ticket offices in many markets. They are increasingly relying on digital media to engage with customers. Alternatively, they may use the services of customer centres, where customers may contact the airline, via a call centre. As a result, individual customers can easily purchase their airline tickets online. In addition, multiple price comparison websites have also brought significant developments in terms of pricing and inventory, for the benefit of travel agents and endcustomers.

Online booking engines allow passengers to make the booking themselves and to pay for their itineraries through their credit or debit cards. Customers will generally receive an electronicticket confirmation with a unique identifier code within 24 hours of their ticket purchase. They may also check-in online and print their boarding passes. Alternatively, they may store their boarding pass on their mobile device or smart phone for easy access at security, and when they board the aircraft. Passengers must make sure that the entire barcode is visible on the screen of their mobile device, particularly when they pass through the terminals' security locations.

Today, the most common way to purchase travel products including airline flights, car rental, cruises, hotel accommodations and other forms of transportation, among others; is through online and mobile search engines. This year, digital travel sales in the U.S. alone will reach $\$ 189.62$ billion, $40.0 \%$ of which will come from mobile devices (eMarketer, 2017). Consumers are increasingly making their travel arrangement through their mobile due to larger smartphone screens and easier payment methods. Moreover, many tourism businesses and online travel agencies have improved their websites and may have introduced user-friendly mobile apps. As a result, many prospective travellers are not only booking their trips, online; but are also searching their itineraries, when they are out and about, via their mobile device. 


\subsubsection{Elements of Travel Websites}

Corporate websites will help the travel and tourism businesses in their distribution strategies, as they improve consumer leads and sales conversions. Clear, differentiated pricing information on service-tiers, provide product options to online prospects. The tourism businesses ought to focus on the benefits they provide, by highlighting their value propositions; rather than simply illustrating their products' features.

Despite the fact that so many transactions are carried out online, the lack of personal interaction in this medium means that even the smallest thing that's out of place on ecommerce pages can rapidly erode the customers' trust in products and businesses. Therefore, businesses could build consumer confidence and trust by using an SSL certificate to make transactions secure, particularly if they are processing credit cards.

The online businesses are expected to articulate their terms and conditions, including any relevant cancellation and refund policies. Moreover, customer-centric businesses should feature their contact details (including an address, telephone and emails) to customers. Many online sites are increasingly offering live chat facilities on their site, to help prospective customers in their queries, or to address their concerns.

If the businesses do not offer such interactions in real time, they still need acknowledge their online prospects' message(s), and inform them that they will be responding to them in reasonable time. Moreover, the use of testimonials from consumers, including; reviews and ratings will serve as proof that the tourism business is providing an adequate level of service to its customers. The positive experiences from customers themselves, will help to improve conversions and sales. The tourism web sites should underline the true benefits of their product. Therefore, they should present relevant written content which will make the product stand out from the rest. In this day and age, attractive web sites are well designed to entertain visitors. The travel sites could also feature a good selection of images and videos. This allows prospective visitors to become familiar with the tourism product. Destination management organisations are increasingly allowing online visitors to zoom in high-res images and video clips in their websites. The interactive images and videos should load as quickly as possible. Any delays of even a couple of seconds would turn off dissatisfied visitors. The speed with which a page loads can be a critical determining factor as to whether visitors may (or may not) commit themselves to lay down their credit card. When designing product pages, it is important 
to consider load speeds, particularly if there are large images, rich interactivity or other media in web pages.

Very often, different product pages may clutter up web pages with excessive calls to action. These pages may contain customer photos, complicated pricing options, unnecessary details on customer support, too many reviews, et cetera. Without good design, these calls to action could easily blend into a confusing mess. While it may be tempting to utilise the web page with many actionable steps, the web sites should be as clear and focused as possible. A good call to action could include high-contrast buttons, call-outs and actionable elements which leave plenty of breathing room to make them stand out.

Online users might not be willing to commit themselves in buying products straight away. Therefore, businesses could entice visitors to fill in their subscriber list to receive exclusive offers, via email. This way, the businesses will be in a position to send newsletters and promotional material to the online prospects, at a later date.

Businesses ought to facilitate their online purchase and transaction confirmation. A complicated funnel could deter the conversion of prospects. The customers who are in the businesses' checkout page should be allowed to finalise their purchase as quickly and efficiently as possible. If their customer experience of their online purchase involves an unnecessary effort to check out from the website; they may have second thoughts on the businesses' quality of service. Therefore, users should not be distracted with anything that will take them away from the businesses' purchasing funnel. It is important to let customers finish their transaction before taking them anywhere else on the website.

\subsubsection{Travel Search Engines}

Many search engines are increasingly offering advantageous deals on travel products. Very often, they may have user-friendly websites that help individual consumers search for the best prices. For example, a flight search may include one-way, return or multiple destinations. The travellers may specify whether they would like to travel in a particular class of service (for example, economy, business or first class). Travellers may also opt for direct services (which 
are usually more expensive), and their search can be narrowed down according to their preferred departure and arrival times (if any).

In addition, many search engines identify their "best flight" option. Their algorithm will usually base their decision on layover time, the length of flight, and departure/arrivals times. They may also let you know if there are cheaper flights available, particularly if there are nearby airports.

Price Alerts: The search engines will enable their users to set a price alert on tourism products. For example, after the users have given details on the travel dates and their email address, they will receive regular emails which will communicate whether the price for the flight (that was searched through the search engines' system) has gone up or down in price.

Travel alerts are convenient for those passengers who are planning their itineraries in advance. Online prospects will be updated on the best time to purchase their flight (in this case).

Flight Deal Websites: Online prospects can find good flight deals by following niche websites that are dedicated to posting such deals. Most of these websites may not necessarily be affiliated with any airline. Very often, consumers may check these websites on a regular basis. Alternatively, they may follow travel and tourism groups through social media.

Flexibility: An inexpensive flight may not always be the right flight for passengers. The prospective customers may demand flexible dates. For instance, they may want to avoid unnecessary overnight stays in random cities (a hotel accommodation may well increase the cost of the travellers' journey). Moreover, there are other important considerations. For example, customers may not be willing to travel to distant airports. They may not like to travel at night, et cetera.

The best flight deals may not last long as search engines may frequently change their flight prices.

Bonus Tip: Many low-cost carriers may not feature all costs in their prices. These "hidden" costs may comprise carry-on baggage fees, checked-baggage charges and seat fees. Customers should check these fees and charges before purchasing a flight with any airline. Such "hidden" costs and expenses are usually disclosed on the airlines' respective websites. In many cases these supplementary fees can be paid in advance. If customers would not pay in anticipation of their flight, they may easily incur additional charges. 
Therefore, the overall best deal should be determined according to flight times, hidden costs, and personal airline preferences.

\subsection{Latest Advances in Travel Distribution}

The development of digital media technologies, particularly the internet and social media are offering a wide range of possibilities to the travel industry. These latest technological advances have enabled many travel businesses, including airlines and hotels to manage their distribution channels in a more efficient and economical way. With the changing landscape of travel ecommerce and the ubiquity of IT solutions which gather, store, and analyse data in a variety of ways; airlines have improved their ability to monitor their performance across channels. Very often, they are in a position to quickly adjust offers. Their prices are usually based on a variety of situations and circumstances, as they optimise communications and transactions.

By using big data and analytics on their customer behaviours, many travel businesses are taking advantage of channel-based distribution. Hence, the distribution networks have come a long way from the ticket counter. Evidently, travel and tourism businesses are leveraging themselves with data-driven marketing, as they seek new customers and prospects. For example, they may increase their profitability from high-yield customers as they are using elaborated pricing and revenue management systems. The travel distribution is evolving from its current passive, rigid, and technology-centric state to a more flexible, dynamic, and passenger-centric environment.

\subsection{The Future of Travel Distribution}

Any changes in the tourism distributive systems may be stimulated by external macro factors such as politics and trade, global and national economies, technological innovations and access to them, et cetera. The airline industry could be affected by increased competition from lowcost carriers, new mergers and acquisitions, and fuel costs, among other issues. However, the commercial future of the tourism industry may also be influenced by other factors, including travel distribution. Tourism businesses can possibly become even more effective in how they sell their products and services; particularly if they deliver positive customer experiences. Tourists perceive value in customer-centric businesses. 
Most probably, in the future, there will be significant improvements in terms of technologically enhanced customer services. Tomorrow's businesses will be serving passengers from geographically-diverse regions. There will be more travellers from emerging markets and developing economies. The travel distribution systems will have to cater for senior citizens, as there are aging populations in many countries. The distributive channels must be designed to accommodate a divergent nature of users. Tourism service providers and their intermediaries will be expected to provide engaging, intuitive shopping experiences that tap into the traveller's discretionary purchases.

The travel businesses will need to embrace new technologies and flexible distribution processes; as outmoded distribution components will be replaced. It is envisaged that new distributive systems will be relying on mobile devices as these technologies enable consumer interaction with speech and voice recognition software. The tourism businesses could possibly leverage themselves with artificial intelligence. They may facilitate their dynamic pricing, as well as personalisation of services. The distributive systems could interface with virtual reality software to help businesses merchandise their products in captivating customer experiences.

Probably, the third-party retailers will continue to form part of the distribution mix. However, many service providers will be using their direct channels to reach their targeted customers. There may be fewer market intermediaries, and online travel agencies will see significant declines. It is very likely, that airlines will not have to pre-file volumes of defined fares through third-parties, as they may not rely on inventory buckets to manage their selling capacity. The airlines must recognise the need to invest in new internal selling systems. Today's passenger service systems already lack the flexibility that airlines require. They are not adequate enough to serve the airlines' flexible and dynamic sales environments. These systems could be replaced with modular retailing platforms. Full Retailing Platforms (FRPs) which will allow airlines to take back the control they require to be better retailers through any distribution channel (Atmosphere, 2016).

Moreover, Google, the multinational technology company, could be playing a much larger role in travel distribution. The technology giant could participate in, and possibly disrupt the tourism industry if it becomes an online travel agency; whether through acquisition or by launching a product of its own. In fact, its travel product, Google Flights is increasing in popularity among travellers. Furthermore, there could be further improvements in online payment facilities, particularly in the development of digital and mobile wallets. 
In the foreseeable future, the travel marketplace will surely introduce new technologies and capabilities; as multiple venture capital firms are increasingly investing in disruptive innovation. There may be new businesses, including private air service operators, who could provide "on-demand" airline services. Alternatively, technology companies could develop or acquire meta-search engines or online travel agencies. Hence, the travel and tourism businesses need to find ways that intentionally overturn decades of outdated, travel distribution practices. The distribution community can choose to innovate and disrupt, or allow others to be leading innovators.

\subsection{Questions}

- Outline the main distributive links between the airline the customer

- Discuss what marketing policies should management adopt with regard to intermediaries.

- Explain how new technologies in travel distribution could improve the airline product?

\subsection{Summary}

The distribution channels refer to all aspects which link the businesses with the consumers. In the past, airlines used to hold sales offices / ticketing offices in city centres and airports. Their distribution network also consisted of tour operators and travel agents who were entrusted with the distribution of tourism products. These intermediaries were usually paid by sales commissions, in return for their services. Today, many of these businesses are not receiving commissions from airlines. Therefore, they had to restructure their operations by reducing their costs. Airlines are also restructuring their business models as they have changed traditional distribution networks. They have reduced their sales offices, and are increasingly using the services of customer call centres that can be contacted on a $24 / 7$ basis.

The development of new technology has resulted in fundamental changes in the distribution of travel products. The most significant developments have taken place in global distribution systems. Moreover, individual and corporate customers are benefiting of ubiquitous 
technologies as they can purchase their online tickets through the internet and from their mobile devices.

In assessing distribution strategies, the travel industry must examine the issues of control and value for money. In addition, the development of mobile devices and their applications, are offering a wide range of possibilities to the travel industry. Ultimately, tomorrow's business must continue to embrace innovative distribution technologies to improve the customer experience. 